\title{
OUT-OF-POCKET HEALTHCARE PAYMENTS AND IMPOVERISHMENT AMONG MIGRANT ADOLESCENT FEMALE HEAD PORTERS IN GHANA: A CROSS SECTIONAL STUDY
}

\author{
${ }^{* 1}$ Alatinga K. A, ${ }^{2,4}$ Kanmiki E. W., ${ }^{3,5}$ Abiiro G. A \\ ${ }^{1}$ Department of Community Development, Faculty of Planning and Land Management, SD Dombo University of Business and \\ Integrated Development Studies, Wa, Ghana \\ ${ }^{2}$ Institute for Social Science Research, University of Queensland, Indooroopilly, QLD, 4068, Australia. \\ ${ }^{3}$ Department of Health Services, Policy, Planning, Management and Economics, School of Public Health, University for Development Studies, Ghana \\ ${ }^{4}$ Alliance for Social Innovation and Livelihood Improvement (ASOLI), Bolgatanga, Upper East Region, Ghana \\ ${ }^{5}$ Department of Population and Reproductive Health, School of Public Health, University for Development Studies, Tamale, Ghana \\ *Corresponding Author's Email: kalatinga@gmail.com
}

\begin{abstract}
Direct out-of-pocket $(O O P)$ payments for healthcare can have devastating effects on vulnerable populations leading to impoverishments. Ghana's National Health Insurance Scheme (NHIS) aims to remove financial hardships associated with seeking healthcare. However, there are concerns that vulnerable sections of the population still face healthcare-related financial hardships. This paper examines the impoverishing effects of $O O P$ healthcare payments and the determinants of impoverishment due to OOP healthcare payments among migrant adolescent female head porters aged 10-19 years in Ghana. A quantitative cross-sectional survey was administered to a sample of 336 respondents who reported ill and sought healthcare within the last 12 months, January-December 2015, prior to the survey in 2016. Impoverishment due to OOP payment was assessed by computing the net income after payment for health care using the World Bank's poverty line of income of $\$ 1.90$ a day converted to 2015 purchasing power parity (PPP) equivalence for Ghana. The results illustrate that poverty incidence increased from 23 percent before OOP payment to 76 percent post OOP payment for healthcare. In a multivariate analysis, primary education [AOR=0.32, 95\%CI=0.15-0.68]; Mamprusi $(A O R=0.41,95 \% C I=0.19-0.87)$ and other ethnic groups [AOR=0.33, 95\%CI=0.14-0.75] compared to Dagomba; > lyear in head portage $(A O R=0.46 ; 0.23$ - 0.95); drug store $(A O R=0.43,95 \% C I=0.19-0.96)$ and home treatment $[A O R=0.20,95 \% C I=0.05-0.85]$ were significantly associated with lower odds, whilst never registering for NHIS (AOR=4.05; 95\%=1.82 - 9.03) or no valid NHIS card (2.29; 95\%CI=1.08 - 4.83), Kumasi city [AOR=5.14; 95\% CI:2.45-10.77] and severity of illness[AOR=2.86, CI 1.49-5.45] were associated with higher odds, of impoverishment due to OOP payment. We recommend that the Ministries of Gender, Children and Social Protection and Health should collaborate to enrol adolescent female head porters onto the NHIS in order to increase their financial risk protection. Government should also put in place policy interventions including skills training and livelihood programmes to increase income levels, and improve the poverty situation of adolescent girl head porters.
\end{abstract}

Keywords: Impoverishment, out-of-pocket healthcare payments, adolescent girls, migrants, Ghana 


\section{Introduction}

Adolescent girls are on the move as migration appears to be one of the most visible signs of globalisation in the $21^{\text {st }}$ century. The World Health Organization estimates that there are about one billion migrants globally, of which internal migrants constitute about 728 million (World Health Organization., 2019). About seventy per cent of global internal migrants are women and adolescent girls below 18 years of age (Gilmore, 2018).

In Ghana, rural-urban migration fuels the urbanization process. Ghana's urban population is estimated to be about $56 \%$ and with a growth rate of $4.25 \%$, it is projected to increase to about $63 \%$ by the year 2025 (Awumbila et al., 2014). Historical antecedents and actions of colonial and postcolonial governments favoured the development of the urban south to the detriment of the rural north in Ghana. This situation, coupled with harsh climatic and environmental conditions and low levels of education, have resulted in the five regions in northern Ghana being the poorest in the country with high levels of food insecurity, malnutrition and deprivation (Ghana Statistical Service, 2018). The Seventh Round of the Ghana Living Standards Survey reported that the highest poverty headcount in Ghana in 2016/17 was found in the five regions of northern Ghana with a poverty incidence of about $68 \%$ (Ghana Statistical Service, 2018). This situation has pushed indigenes, including adolescent girls aged 10-19 years from these impoverished communities in northern Ghana to migrate to the urban centres of southern Ghana in search of greener pastures. A major economic activity of these female adolescent migrants from northern Ghana is head potering business popularly known in Ghana as "Kayayoo"- which is the carrying of goods on their heads for shoppers or traders within the commercial centres or markets of the big cities for a fee. Challenges in accessing health care among these migrant adolescent girls and women from northern Ghana who work as head porters in the cities of Accra and Kumasi have been documented (Lattof, 2018; Sabutey, 2014).
The impoverishing effect of out-of-pocket (OOP) payments for healthcare on individuals and households has been an issue of global health policy concern since the Alma Ata declaration of health for all in 1978 (World Health Organization, 1978). The Alma Ata declaration required countries all over the world to develop innovative ways to improve access to healthcare for their citizens (World Health Organization, 1978). The recent United Nations Sustainable Development Goals (SDGs) reinforced the urgent need for ensuring universal access to quality, affordable and essential health care devoid of financial, geographical or any other barriers (United Nations General Assembly, 2015).

In sub-Saharan Africa (SSA), many national health programmes have prioritized universal health coverage (UHC) and measures such as health insurance have been taken to integrate UHC within health programmes (World Health Organization, 2010). Health insurance is considered a key mechanism for improving financial risk protection from catastrophic healthcare cost by pooling funds that enable cross-subsidization between the rich and the poor for the healthy as well as the sick (World Health Organization, 2010). In sub-Saharan Africa, where evidence shows that the highest burden of diseases and catastrophic health expenditure are faced by the poor, health insurance presents a good avenue for improving financial risk protection (World Health Organization, 2010). Several countries in the sub-region including Ghana, Kenya, Tanzania, Ethiopia, and Rwanda have implemented health insurance schemes for this reason (Fenny et al., 2018). While Ghana's national health insurance scheme (NHIS) by law is supposed to cover the whole population with premium exemptions for selected sections of its population (National Health Insurance Authority, 2013), Kenya and Tanzania operate separate health insurance schemes for the formal and informal sectors of their population. Ethiopia and Rwanda on the other hand have community-based health insurance programmes (Fenny et al., 2018). The 
modes of operation of each of these insurance schemes differ in terms of the approach to expanding coverage, exemptions, co-payments, revenue pooling etc (Fenny et al., 2018). However, the core objectives are the pooling of resources, reducing OOP payments at point of care, financial risk protection and ultimately contributing to achieving UHC in these countries. Thus, being an active member of a health insurance scheme can help reduce health care induced poverty among the head porters.

This notwithstanding, progress in health service coverage is fraught with gaps and OOP healthcare payments abound, pushing about 11 million Africans into poverty annually (World Bank, 2016). Ghana is among the leading UHC implementing countries in Africa. By intensifying the scale-up of community-based primary healthcare delivery and implementing Ghana's National Health Insurance programme among others, Ghana's health sector aims to expand the range of service coverage towards the achievement of UHC (World Bank, 2016). Despite this keen national interest in UHC reforms within SSA, rapid increase in population movement puts vulnerable migrants at the risk of being excluded from UHC programmes (International Organization for Migration, 2020). Literature suggests migration, especially among vulnerable populations such as migrant adolescent girls, is associated with public health challenges such as sexual exploitation and inadequate access to healthcare (Boateng et al., 2017).

Previous studies have provided insights of the low active enrolment of these female head porters onto the NHIS and the struggles of pregnant young migrant head porters in accessing the free maternal healthcare under Ghana's NHIS (Lattof, 2018; Yiran et al., 2015). Some studies have also examined OOP health expenditure and its impoverishing effects on the general population in sub-Saharan Africa and Ghana in particular (Akazili et al., 2017; Attia-Konan et al., 2019; Navarrete et al., 2019; Kanmiki et al., 2019; Okoroh et al., 2020; Wagstaff et al., 2020). The results of these studies illustrate that huge impoverishments due to OOP health expenditure occur among the poor and vulnerable sub-groups in the general population and that urbanization increases OOP health expenditure (Attia-Konan et al., 2019; Wagstaff et al., 2020). For instance, people in the Ivorian capital, Abidjan averagely incurred 1.6 times OOP health expenditure relative to rural dwellers, and that women incurred $26 \%$ of OOP health expenditure higher than men (AttiaKonan et al., 2019). In Ghana, research generally indicates that individuals with a valid national health insurance cover are less likely to be impoverished due to health expenditure but huge inequalities exist in the benefits of national health insurance on financial protection from out-ofpocket payments (Akazili et al., 2014; Navarrete et al., 2019). Using a poverty line of $\$ 1.25 /$ day income, evidence shows that OOP contributes to about nine percent increase in the absolute number of the poor and a $31 \%$ deepening of poverty levels in Ghana (Akazili et al., 2017). Interestingly, the poorer, less educated, women and informal sector workers are reported to have an increased risk of impoverishment due to OOP healthcare expenditure in Ghana (Navarrete et al., 2019; Okoroh et al., 2020).

However, there is paucity of knowledge on the incidence of OOP healthcare payment and impoverishment due to OOP payment among specific vulnerable groups like migrant adolescent girl head porters in Ghana. To the best of our knowledge, this is the first study to investigate the incidence of impoverishment and correlates of impoverishment due to OOP payments among migrant female head porters in Ghana. The objectives of this study are therefore, threefold. First, the study examines the incidence of OOP payment among migrant adolescent female head porters in Ghana. Second, it assesses the level of impoverishment due to OOP payments for healthcare. Finally, the study determines the factors associated with impoverishment due to OOP payments among these girls. Evidence generated by this study has the potential to contribute to 
interventions and strategies to improving access to healthcare for vulnerable populations in Ghana.

\section{Out-Of-Pocket Healthcare Expenditure and Impoverishment}

Effective health services coverage and financial protection are core dimensions of UHC (Abiiro and De Allegri, 2015). Put differently, UHC describes the situation where all people, irrespective of their socio-economic status (SES), gender, and place of residence have access to healthcare services of reasonable quality devoid of undue financial hardship (World Health Organization, 2010). In spite of the generous benefit package of Ghana's NHIS program, both the insured and uninsured continue to be faced with OOP payments. For instance, a study in northern Ghana found that the average OOP payment of in-patient cost for treating malaria (the commonest disease condition in Ghana) per case for the insured was $\mathrm{GH} \phi 4$ (US\$2.7) compared to GH $\not 6.4(\mathrm{US} \$ 4.3)$ for the uninsured in the year 2011 (Dalaba et al., 2014). Another study also found significantly lower OOP payments for the insured compared to the uninsured, revealing that in NHIS accredited facilities, $6 \%$ of insured households incurred catastrophic OOP payments as against $23.2 \%$ of the uninsured (Kusi et al., 2015). Other studies have reported that health insurance enrolment reduced OOP payments by $86 \%$ and protected households against poverty and catastrophic health spending by $7.3 \%$ and $3 \%$, respectively (Aryeetey et al., 2016).

Without financial protection, households or individuals seeking healthcare may be pushed into poverty or those who are already poor will remain trapped in poverty due to direct out-of-pocket payments at the point of care (Salari et al., 2019). Even so, guaranteeing financial protection for the entire population may be challenging in resource constrained countries, as there is the risk that poor and less advantaged segments of the population could be left behind (Boerma et al., 2014). Studies in 133 countries report that globally, 599 million people incurred catastrophic health spending in
2000, and this figure increased to 741 million people in 2005, and further increased to 808 million people in the year 2010 (Salari et al., 2019; Wagstaff, Flores, Hsu, et al., 2018). Catastrophic heath expenditure is said to occur when an individual's or a household's total OOP health payments equal or exceed $40 \%$ of the individual's or household's income, and this kind of expenditure pushed about 122 million people into poverty in the year 2010 (Salari et al., 2019).

Impoverishment due to OOP healthcare expenditure occurs when an individual's or household's income which was above the poverty line before OOP healthcare payment (prepayment) falls below the poverty line after paying for healthcare (post-payment), pushing such individuals or households from non-poor status to poor status (Hailemichael et al., 2019). A global study in 122 countries analysing the impoverishing effects of OOP healthcare payments reported that $1.4 \%$ of the world's population were impoverished at the $\$ 1.90$ per day poverty line (Wagstaff, et al., 2018). The authors conclude that OOP health expenditure can increase the poverty head count and the depth of poverty by reducing household resources for non-health budget items (Wagstaff, et al., 2018).

Literature suggests that income levels, education, occupation, social class, gender, place of residence and health insurance status, among others are associated with impoverishment (Goudge et al., 2009; Li et al., 2012; World Health Organization., 2010). Indeed, a WHO Commission on Social Determinants of Health (CSDH) developed a conceptual framework that in part identified how these factors work together to influence the exposure of individuals to ill-health conditions within social hierarchies/positions, which then affect their ability to access quality healthcare equitably and the outcomes thereof (World Health Organization., 2010). The association between these factors and impoverishment appear logical because poor living conditions expose people to ill health and affect their ability to access healthcare as they may be compelled to sell off their assets in an 
effort to pay for the medical expenses of the sick person. A study found that highly vulnerable households frequently had challenges meeting their minimum food needs, and struggled to sustain their livelihood status due to illness (Goudge et al., 2009). Consequently, such households may decide to self-treat due to unaffordable health expenditure. A study from China reports that households in rural settings had higher rates of poverty and those households without insurance were at higher risk of incurring catastrophic health expenditure ( $\mathrm{Li}$ et al., 2012).

It has been cautioned that the proportion of the population that is supposed to be covered by health insurance schemes or by national or subnational health services is a poor indicator of financial protection (Wagstaff, et al., 2018). Researchers argue that increasing the share of gross domestic product spent on health is not sufficient to reduce incidence of catastrophic payment - what is rather required is increasing the share of total health expenditure that is prepaid, particularly through taxes and mandatory contributions (Wagstaff, et al., 2018). A study in Ghana found that even relatively richer households are impoverished by OOP healthcare payments, and that about 396,000 more people are being pushed into poverty by paying OOP for healthcare (Akazili et al., 2017).

In the light of this literature, it is important that policymakers and implementers factor in mechanisms through which vulnerable sections of the population can be protected against direct OOP payments and their associated devastating impoverishing effects. To achieve this, research evidence on how sections of the population are faring is pivotal in guiding the design of support systems. Social protection schemes for vulnerable groups such as migrant female head porters could be a good start. This current study is contributing to this goal by assessing the incidence of OOP payments and its impoverishing effects on vulnerable adolescent migrant female head-potters in Ghana.

\section{Methodology \\ Study sites}

The study was conducted in Accra and Kumasi, the two largest cities in Ghana. Accra and Kumasi are the two most urbanized cities in Ghana where adolescent girls from northern Ghana migrate to and engage in carrying loads of goods on their heads. Kumasi is centrally located in Ghana and serves as a traversing point to most parts of the country (Alatinga, 2019) while Accra is geographically located along the coast of Ghana. These two cities alone have $40 \%$ of the entire human resources available in the health sector in Ghana, and home to most modern healthcare facilities in the country (Ghana Health Service, 2017).

\section{Study design, target population and sampling}

A quantitative cross-sectional design was used in this study. The design was cross-sectional because respondents were contacted and data collected from them at a point in time and could not be followed over a time period. The study targeted adolescent girls between the ages of 10-19 years in the Kayayo trade. Cognizant of the challenges associated with sampling hard-to-reach and migrant populations using standard probability methods (Gile \& Handcock, 2010), and the fact that there is paucity of accurate statistics on female head-porters in Ghana (Boateng et al., 2017; Lattof, 2018) timelocation sampling approach was deemed appropriate for generating random estimates for the study population of migrant adolescent girls (Reichel \& Morales, 2017). The time-location sampling approach assumes that by randomly sampling pre-defined locations where hard-toreach populations are known to reside using "centres of aggregation techniques", it is possible to reach and cover the targeted population adequately (Reichel \& Morales, 2017). This strategy involves first developing a list of all centres of aggregation of the targeted population. Next is to randomly sample some centres and then randomly select from the sampled centres of aggregation the final respondents (Reichel \& Morales, 2017). In Accra, Agbogboloshie market, 
Tema Station and Madina markets were randomly selected while Aboabo Station, Kejetia market, and Roman Hill were randomly selected for Kumasi. At the centres of aggregation, we listed all the girls aged 10-19 years. We physically counted all the girls who were present in the chosen centres of aggregation, and then generated a list based on this count. A total of 1,006 girls were listed from the physical counting from all six centres of aggregation in the two cities. We then used this list as the sampling frame. Based on this sampling frame, and to give all the girls equal chances of being selected, we then randomly sampled 253 girls from Accra and 250 from Kumasi respectively in the form of a lottery, bringing the total sample size to 503 respondents. However, this paper used data from 336 respondents representing those girls who reported ill and sought healthcare between January and December 2015, that is, the last 12 months prior to the study in 2016.

\section{Data collection and analysis}

A survey questionnaire was used to collect the data. The questionnaire collected information including the socio-demographics of the respondents, income, poverty status, healthcare-seeking within the last 12 months, place of seeking care, severity of illness and OOP payment for care. Data on daily income was solicited directly from the respondents. With regards to illness related costs, only respondents who fell ill or injured and sought care in the last 12 months preceding the survey were asked questions. The questions focused on collecting data on healthcare expenditure including the cost of drugs, cost of laboratory and X-ray services as well as the cost of hospitalization. In order to administer the survey questionnaire, appointments were scheduled with the girls who were selected and agreed to participate in the study. For those girls who had their personal mobile phones, the research assistants took their phone numbers for the purposes of follow up for the surveys. Those who did not have personal mobile phones provided the phone numbers of their friends or relatives. The questionnaire was mostly administered on Sundays when the girls were resting or washing their clothes. All copies of the the questionnaire were administered in person.

The data was entered into a database using Epidata and then exported into STATA version 14.0 for analysis. Chi-square test and binary logistic regression models were used to analyse the data. OOP for healthcare was measured as a direct payment made in accessing healthcare by study respondents who reported having been sick and sought care in the last 12 months prior to the survey in 2016. We used the international poverty line of $\$ 1.90$ a day to determine the incidence of poverty (World Bank, 2017). Respondents whose daily income fell below the World Bank's poverty line of $\$ 1.90$ a day were classified as poor and those with income above $\$ .1 .90$ were classified as not poor (World Bank, 2017). Impoverishment due to OOP healthcare payment was then determined by computing the net income after healthcare payment and incomes below \$1.90 Purchasing Power Parity (PPP) after OOP payments were categorized as having been impoverished due to OOP payment. We assessed the determinants of impoverishment due to OOP payments in two ways. We initially did a bivariate analysis using the chi-square test of association and followed up with a binary logistic regression model. Variables included in this analysis were: age, education, marital status, ethnicity, religion, years of working as head porter, city of migration, childbirth since becoming a head porter, SES, NHIS registration and place of accessing healthcare. Our choice of the logistic regression model is informed by the fact that our outcome variable is dichotomous in nature. The logistics regression model is presented below as:

$$
\operatorname{Logit}(\mathbf{Y})=\beta_{0}+\beta_{1} X_{1}+\beta_{2} X_{2} \ldots \beta_{i} X_{i}
$$

Where Y represents the binary outcome variable for impoverishment due to OOP healthcare payments, $\boldsymbol{\beta}_{\mathbf{0}}$ is the intercept or constant term, $\boldsymbol{\beta}_{\mathbf{1}}, \boldsymbol{\beta}_{\mathbf{2}} \ldots \boldsymbol{\beta}_{\boldsymbol{i}}$ are the coefficients of the explanatory variables and $\mathrm{X}_{1}, \mathrm{X}_{2} \ldots . . \mathrm{X}_{\mathrm{i}}$ are the independent/explanatory variables. Significant association was determined 
by a $p$-value of $\leq 0.05$ and $95 \%$ confidence interval (CI). All adjusted odd ratios (AORs) and their corresponding 95\% CIs have been reported in the multivariate analysis.

\section{Results}

\section{Background Characteristics of Research}

Participants

Table 1 provides the background characteristics of the study respondents. Of the 336 adolescent girls who reported ill and sought healthcare, 128 (38.1\%) had not attained any form of formal education while only $23(6.9 \%)$ were educated up to secondary level or had technical education. $56(16.7 \%)$ of these adolescent girls reported that they were already married and 280 (83.3\%) were single. About 183 $(54.5 \%)$ of the respondents have been engaged in head porter job for less than a year while 62 (18.5\%) have been engaged for up to 1 year. The rest have been in this business for over one year.

\begin{tabular}{|c|c|c|c|c|c|}
\hline $\begin{array}{l}\text { Background } \\
\text { Characteristics }\end{array}$ & $\begin{array}{l}\text { Freq. }(\mathrm{N}= \\
\text { 336) }\end{array}$ & Percent $(\%)$ & $\begin{array}{l}\text { Background } \\
\text { Characteristics }\end{array}$ & $\begin{array}{l}\text { Freq. } \\
(\mathbf{N}=336)\end{array}$ & Percent $(\%)$ \\
\hline \multicolumn{3}{|l|}{ Level of Education } & \multicolumn{3}{|c|}{ Childbirth since becoming a Head Porter } \\
\hline None & 128 & 38.1 & Yes & 35 & 10.4 \\
\hline Primary & 85 & 25.3 & No & 301 & 89.6 \\
\hline JSS/JHS & 100 & 29.8 & \multicolumn{3}{|l|}{ Current pregnancy status } \\
\hline Secondary/Technical & 23 & 6.9 & Pregnant & 11 & 3.3 \\
\hline \multicolumn{3}{|l|}{ Marital Status } & Not Pregnant & 325 & 96.7 \\
\hline Married & 56 & 16.7 & \multicolumn{3}{|l|}{ SES (Wealth Index) } \\
\hline Single & 280 & 83.3 & Poor & 77 & 22.9 \\
\hline \multicolumn{3}{|l|}{ Ethnic Group } & Not poor & 259 & 77.1 \\
\hline Dagomba & 138 & 41.1 & \multicolumn{3}{|l|}{ NHIS Registration } \\
\hline Mamprusi & 140 & 41.7 & Yes, has active card & 100 & 29.8 \\
\hline Others & 58 & 17.3 & Yes, but no active card & 102 & 30.4 \\
\hline \multicolumn{3}{|l|}{ Religion } & Not Registered & 134 & 39.9 \\
\hline Islam & 303 & 90.2 & \multicolumn{3}{|l|}{ Severity of Illness } \\
\hline Others & 33 & 9.8 & Mild/Moderate & 112 & 33.3 \\
\hline \multicolumn{3}{|c|}{ Number of Years Worked as a Head Porter } & Severe & 224 & 66.7 \\
\hline$<1$ year & 183 & 54.5 & \multicolumn{3}{|l|}{ Place of Care } \\
\hline 1year & 62 & 18.5 & Modern health facility & 82 & 24.4 \\
\hline \multirow{3}{*}{$\begin{array}{l}\text { More than } 1 \text { year } \\
\text { City of Migration } \\
\text { Accra }\end{array}$} & 91 & 27.1 & \multirow{5}{*}{$\begin{array}{l}\text { Drug stores } \\
\text { Traditional/home/other }\end{array}$} & \multirow{4}{*}{$\begin{array}{l}238 \\
16\end{array}$} & \multirow{3}{*}{$\begin{array}{l}70.8 \\
4.8\end{array}$} \\
\hline & & & & & \\
\hline & 191 & 56.9 & & & \\
\hline Kumasi & 145 & 43.1 & & & \\
\hline Total & 336 & 100.0 & & 336 & 100.0 \\
\hline
\end{tabular}

Source: The Authors' (2021)

Of the 336-study sample, 191 (56.9\%) were migrants in Accra while the rest were migrants in Kumasi. 35 (10.4\%) of the respondents had given birth at least once since they became head porters and $11(3.3 \%)$ reported being pregnant at the time of the study. About $100(29.8 \%)$ respondents indicated that they were actively registered with the
NHIS, 102 (30.4\%) were registered but did not have active NHIS cards in order to access healthcare under the NHIS - this means that this category of respondents did not renew their NHIS membership when it expired, and 134 (39.9\%) of the respondents had never registered with the NHIS. $224(66.7 \%)$ of the study sample self-rated 
their illness as severe while $112(33.3 \%)$ rated theirs as mild or moderate. Majority of the study sample sought healthcare from drug stores while 82 $(24.4 \%)$ received care from modern health facilities comprising of public hospitals, health centres and private hospitals and $16(4.8 \%)$ received care from either traditional healer at home or did selftreatment.

\section{Healthcare Seeking and Out-of-pocket Payment within the last 12 Months}

Figure 1 presents a flow chart of healthcare seeking and OOP payments among the study respondents over the last 12 months prior to the survey. Out of the 336 head porters who reportedly fell ill and sought healthcare within the period, 299 (89\%) of them paid OOP to access healthcare and only 37 $(11 \%)$ did not.

\section{Figure 1: Healthcare Seeking and OOP Payment}

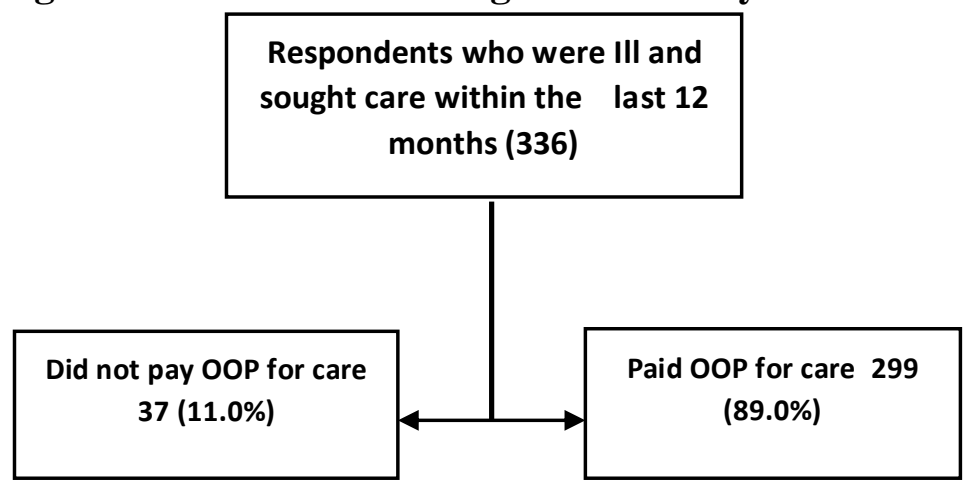

Source: The Authors (2021)

Overall, the average OOP payments made was $\mathrm{GH} \phi$ 30.9 (US\$6.2), with a minimum OOP payment being $\mathrm{GH} \phi 0.5$ and a maximum of $\mathrm{GH} \phi 550$ (US\$110). In terms of cost components, the average OOP payment for consultations was $\mathrm{GH} \varnothing$
58.5(US\$11.7), OOP for drugs was $\mathrm{GH} \varnothing 25.0$ (US\$5.0), and average for laboratory was $\mathrm{GH} \phi$ 123.4(US\$24.7) while that of surgery was averaged at $\mathrm{GH} \varnothing 469.4$ (US\$93.9). About 128 (95.5\%) of those not registered on the national health insurance paid OOP for healthcare. Also, 87 (85.3\%) of those registered but without active NHIS cards paid OOP whereas $84(84 \%)$ of active registered insurance holders paid OOP for healthcare. Those with active health insurance incurred an average cost of $\mathrm{GH} \phi$ 20.7 (US\$4.1) while those without insurance incurred an average cost of $\mathrm{GH} \phi 31.5$ (US\$6.3).

\section{Impoverishment due to OOP Healthcare Payment}

As illustrated in Table 2, the average daily income of the adolescent head-porters ranges between $\mathrm{GH} \phi 19.65(\sim 3.3)$ and $\mathrm{GH} \varnothing 10.88(\sim 1.8)$ in Accra and Kumasi respectively. The minimum daily income also ranges from $\mathrm{GH} \varnothing 2.0(\sim \$ 0.4)$ in Accra to $\mathrm{GH} \varnothing 0.5(\sim \$ 0.1)$ in Kumasi. Using the World Bank poverty line of earnings of $\$ 1.9$ per day PPP, $259(77.1 \%)$ of the head porters were not poor while $77(22.9 \%)$ of them were poor before OOP healthcare payments. After computing the net income of the head porters after paying OOP for healthcare services, we found that majority-256 $(76.2 \%)$ of the young head porters were impoverished and only $80(23.8 \%)$ of them were not. These results indicate that overall, poverty incidence among the migrant adolescent head porters increased from $22.9 \%$ before OOP payment to $76.2 \%$ after OOP payment for healthcare. Among the actively insured, poverty incidence increased to $69(69.0 \%)$ while it increased to 115 $(85.8 \%)$ for the uninsured. This scenario suggests that the impoverishing effects of OOP among the adolescent girls is very high. 
Table 2: Daily Income Distribution of Head porters by City of Migration Destination

\begin{tabular}{|c|c|c|c|}
\hline Statistic & Accra & Kumasi & Full Sample \\
\hline Sample Size & $191(57 \%)$ & $145(43 \%)$ & $336(100 \%)$ \\
\hline Minimum income GHC (US\$) & $\begin{array}{l}2.00 \\
(\$ 0.40)\end{array}$ & $\begin{array}{l}0.50 \\
(\$ 0.10)\end{array}$ & $\begin{array}{l}0.50 \\
(\$ 0.10)\end{array}$ \\
\hline Maximum income GHC (US\$) & $\begin{array}{l}80.00 \\
(\$ 15.69)\end{array}$ & $\begin{array}{l}80.00 \\
(\$ 15.69)\end{array}$ & $\begin{array}{l}80.00 \\
(\$ 15.69)\end{array}$ \\
\hline Median (IQR) in GHC & $15(70-2)$ & $10(20-5)$ & $15(70-2)$ \\
\hline Mean (SD) in GHC & $\begin{array}{l}19.65 \\
(16.26)\end{array}$ & $10.88(7.02)$ & $\begin{array}{l}15.87 \\
(13.78)\end{array}$ \\
\hline $\begin{array}{l}\text { Income below the poverty line } \$ 1.90 \text { per day PPP before OOP payment } \\
\text { for healthcare }\end{array}$ & $43(22.51 \%)$ & $34(23.45 \%)$ & $77(22.92 \%)$ \\
\hline $\begin{array}{l}\text { Income below the poverty line } \$ 1.90 \text { per day PPP after OOP payment } \\
\text { for healthcare }\end{array}$ & $\begin{array}{l}130 \\
(68.06 \%)\end{array}$ & $\begin{array}{l}126 \\
(86.90 \%)\end{array}$ & $\begin{array}{l}256 \\
(76.19 \%)\end{array}$ \\
\hline
\end{tabular}

Source: The Authors' (2021)

Table 3 presents results of bivariate analysis of factors associated with impoverishment after OOP payment. Of the variables tested using chi-square test of association, ethnicity, period of working as head porter, city of destination, NHIS registration status, having a severe sickness in the past 12 months and place of seeking care were found to be significantly associated with impoverishment due to OOP payment ( $\mathrm{p}$-value $<0.05$ ).

The results of the binary logistic regression are presented in Table 4. After controlling for other confounding factors, education, ethnicity, period of working as head-porter, city of destination, severity of illness, NHIS registration status and place of seeking care were significantly associated with impoverishment due to OOP payment. However, marital status, religion, child conception during head porter job and current pregnancy status were not significantly associated with impoverishment. Respondents who had primary education were significantly less likely to be impoverished by OOP payment compared to those without any formal education $(\mathrm{AOR}=0.32$, p-value $=0.003, \mathrm{CI}: 0.15-0.68)$.

Also, respondents who indicated that they were Mamprusi ( $A O R=0.41, C I=0.19-0.87)$ and other ethnic groups, including Gonja, Waala, Kusasi, Dagaaba, Kassena, Grusi, and Ewes $[A O R=0.33$, p-value=0.008, $C I=0.14$ 0.75 ] had 0.41 and 0.33 less odds of being impoverished by OOP healthcare payment respectively as compared to Dagomba. Study respondents who had been in the head porter business for over one year had 0.46 less odds of being impoverished due to OOP compared with those who had less than one year of engagement as head porters $(\mathrm{AOR}=0.46$, p-value $=0.035 \mathrm{CI} 0.23-0.95)$. 
Table 3: Bivariate Analysis (Chi-square test) of Impoverishment due to Healthcare Payments

\begin{tabular}{|c|c|c|c|c|c|}
\hline \multicolumn{2}{|c|}{ Variables } & $\begin{array}{c}\text { Not Impoverished } \\
(\%)\end{array}$ & $\begin{array}{l}\text { Impoverished } \\
(\%)\end{array}$ & $\begin{array}{l}\text { Chi-Square } \\
\left(\chi^{2}\right) \text { statistic }\end{array}$ & $P$ value \\
\hline \multirow[t]{4}{*}{ Level of Education } & None & $23(18)$ & $105(82)$ & & \\
\hline & Primary & $29(34)$ & $56(66)$ & 7.632 & 0.054 \\
\hline & JSS/JHS & $22(22)$ & $78(78)$ & & \\
\hline & Secondary/Technical & $6(26)$ & $17(74)$ & & \\
\hline \multirow[t]{2}{*}{ Marital Status } & Married & $11(20)$ & $45(80)$ & 0.686 & 0.408 \\
\hline & Single & $69(25)$ & $209(75)$ & & \\
\hline \multirow[t]{3}{*}{ Ethnic Group } & Dagomba & $20(14)$ & $118(86)$ & & \\
\hline & Mamprusi & $36(26)$ & 104(74) & $16.753 * * *$ & $<0.001$ \\
\hline & Others & $24(41)$ & $34(59)$ & & \\
\hline \multirow[t]{2}{*}{ Religion } & Islam & $69(23)$ & 234(77) & 1.830 & 0.176 \\
\hline & Others & $11(33)$ & $22(67)$ & & \\
\hline Period of working as a & $<1$ year & $34(19)$ & $149(81)$ & & \\
\hline \multirow[t]{2}{*}{ Head Porter } & 1year & $13(21)$ & 49(79) & $10.816 * *$ & 0.004 \\
\hline & Above 1year & $33(36)$ & $58(64)$ & & \\
\hline \multirow[t]{2}{*}{ City of migration } & Accra & $61(32)$ & $130(68)$ & & \\
\hline & Kumasi & $19(13)$ & $126(87)$ & $16.117 * * *$ & $<0.001$ \\
\hline \multirow{2}{*}{$\begin{array}{l}\text { Child birth since } \\
\text { becoming a Head Porter }\end{array}$} & Yes & $8(23)$ & $27(77)$ & & \\
\hline & No & $72(24)$ & $229(76)$ & 0.019 & 0.889 \\
\hline \multirow[t]{3}{*}{ Current pregnancy status } & Pregnant & $2(18)$ & $9(82)$ & & \\
\hline & Not Pregnant & $78(24)$ & $247(76)$ & 0.199 & 0.656 \\
\hline & Yes, has valid card & $31(31)$ & $69(69)$ & & \\
\hline \multirow[t]{2}{*}{ NHIS registration } & Yes, but no valid card & $30(29)$ & $72(71)$ & $11.466^{* *}$ & 0.003 \\
\hline & Not Registered & $19(14)$ & $115(86)$ & & \\
\hline \multirow{2}{*}{$\begin{array}{l}\text { Severe sickness in the } \\
\text { past } 12 \text { months }\end{array}$} & not severe & $40(36)$ & $72(64)$ & $13.125^{* * *}$ & $<0.001$ \\
\hline & Severe & $40(18)$ & $184(82)$ & & \\
\hline \multirow[t]{3}{*}{ Place of seeking care } & Modern Health Facility & $12(15)$ & $70(85)$ & $7.747 *$ & 0.021 \\
\hline & Drug stores & $61(26)$ & $177(74)$ & & \\
\hline & Traditional/home/other & $7(44)$ & $9(56)$ & & \\
\hline
\end{tabular}

Source: The Authors' (2021). *** $\mathrm{p}<0.001 * * \mathrm{p}<0.01, * \mathrm{p}<0.05$

Adolescent female head-porters whose city of migration was Kumasi were 5.14 times more likely to be impoverished as a result of OOP healthcare payment compared to those whose city of migration was Accra (AOR=5.14, p-value=0.000, CI $2.45-10.77)$.

Table 4: Binary Logistic Regression results on factors Associated with Impoverishment after Paying for Healthcare

\begin{tabular}{lcc}
\hline VARIABLES & Adjusted Odd Ratios & Confidence Intervals \\
\hline Education (Compared with None) & $0.32^{* *}$ & $(0.15-0.68)$ \\
Primary & 0.59 & $(0.26-1.33)$ \\
JSS/JHS & 0.90 & $(0.25-3.21)$ \\
Secondary/Technical & & $(0.39-2.70)$ \\
Marital Status (Compared with Married) & 1.03 & $(0.19-0.87)$ \\
Single & & $(0.14-0.75)$ \\
Ethnic Group (Compared with Dagomba) & $0.41^{*}$ & $(0.25-1.67)$ \\
Mamprusi & $0.33^{* *}$ & \\
$\begin{array}{l}\text { Others } \\
\text { Others }\end{array}$ & 0.65 & \\
Period of working as a Head Potter (Compared with <1year) &
\end{tabular}




\begin{tabular}{|c|c|c|}
\hline 1year & 0.59 & $(0.26-1.34)$ \\
\hline Above 1year & $0.46^{*}$ & $(0.23-0.95)$ \\
\hline \multicolumn{3}{|c|}{ City of migration (Compared with Accra) } \\
\hline Kumasi & $5.14 * *$ & $(2.45-10.77)$ \\
\hline \multicolumn{3}{|c|}{ Child birth since becoming a Head Porter (Compared with yes) } \\
\hline No & 1.10 & $(0.35-3.45)$ \\
\hline \multicolumn{3}{|c|}{ Current pregnancy status (Compared with Pregnant) } \\
\hline Not Pregnant & 0.30 & $(0.04-2.48)$ \\
\hline \multicolumn{3}{|c|}{ NHIS registration (Compared with Yes has valid card) } \\
\hline Yes but no valid card & $2.29 *$ & $(1.08-4.83)$ \\
\hline Not Registered & $4.05 * *$ & $(1.82-9.03)$ \\
\hline \multicolumn{3}{|c|}{ Severe sickness (Compared with not severe) } \\
\hline Severe & $2.86^{* *}$ & $(1.49-5.45)$ \\
\hline \multicolumn{3}{|c|}{ Place of seeking care (Compared with Modern Health Facility) } \\
\hline Drug stores & $0.43^{*}$ & $(0.19-0.96)$ \\
\hline Traditional/home/other & $0.20^{*}$ & $(0.05-0.85)$ \\
\hline Constant & $11.29 *$ & $(1.05-120.91)$ \\
\hline Observations & 336 & \\
\hline
\end{tabular}

Source: The Authors' (2021)

Health insurance registration status was found to be a significant predictor of impoverishment due to OOP payment. Those who did not have active NHIS cards were 2.29 times more likely to be impoverished due to OOP payment while those who had never registered with the NHIS were 4.05 times more likely to be impoverished due to OOP payments as compared to those who were actively registered on the NHIS $(\mathrm{AOR}=4.05$, pvalue $=0.001$, CI $1.82-9.03$ ). Also, respondents who indicated that their illness was severe were 2.86 times more likely to be impoverished by OOP payments compared with those whose illnesses were mild or moderate $(\mathrm{AOR}=2.86$, $\mathrm{p}$-value $=0.001$, CI 1.49 - 5.45). Place of seeking healthcare was also found to have a significant association with impoverishment due to OOP payment. Study respondents who sought care at home, traditional healers or did self-treatment had 0.20 less odds of being impoverished from OOP payments compared to those who sought care from modern health facilities $(\mathrm{AOR}=0.20, \mathrm{p}$-value $=0.029$, CI 0.05 $0.85)$.

\section{Discussion}

This study examined the incidence of OOP payment and determinants of impoverishment due to OOP payments among vulnerable migrant adolescent head porters in two major cities of Ghana. This study revealed that among vulnerable populations such as migrants in the informal sector, the incidence of OOP payment for healthcare is very high $(89.0 \%)$ relative to findings from other studies. Akazili et al., (2017) and Ekholuenetale and Barrow (2021) found that rich individuals or households were more likely to incur OOP payments. For example, in their study in Ghana, Akazili et al. (2017) found that $10.9 \%$ of the population incur OOP payments, and concluded that richer households incurred more OOP relative to poorer ones. Ekholuenetale and Barrow (2021) found that $17 \%$ of women from wealthy home paid OOP for health care.

While some previous studies found average OOP health payments around US \$ 4.3 and US \$ 2.7 for uninsured and insured respectively among the general population (Dalaba et al., 2014), our study found that even insured migrant adolescent female head-porters paid US $\$ 4.1$ while the uninsured ones paid an average of US\$6.3 OOP. A recent study in 
Ghana reported that $49.7 \%$ uninsured clients made OOP payments for out-patient care while $46.9 \%$ of the insured clients paid OOP, and that on average insured clients paid \$5.5 OOP for healthcare. Also while previous studies found that $6 \%$ and $23.2 \%$ of insured and uninsured incur catastrophic OOP payments (Kusi et al., 2015), our study revealed that poverty incidence increased from $23 \%$ before OOP payment for healthcare to $76 \%$ after OOP payment for care, with the uninsured having the highest burden of impoverishment of $85.8 \%$ compared to $69 \%$ for the actively insured.

Migrant adolescent female head potering with no formal education, Dagomba ethnic origin, those engaged in head potter business within less than a year, migrants in Kumasi, those not actively registered on NHIS, those who had severe health conditions and those who sought healthcare from modern health facilities were significantly more likely to be impoverished due to OOP payments.

Compared to those participants without education, primary educational status was found to have a significant association with impoverishment due to OOP payment. A study on household impoverishment arising from OOP payment also found significant association between educational status of household head and impoverishment (Aregbeshola \& Khan, 2017). Although, the income received from head porter business did not vary with educational attainment, education could lead to better management of income and expenditure thus our results attest to the influence educational attainment could have on empowering vulnerable people from OOP healthcare payments induced poverty.

Respondents belonging to the Dagomba ethnic group were found to be more likely to be impoverished due to OOP payment. It is unclear how respondents' ethnicity could impact on impoverishment due to OOP payment among this vulnerable cohort of females. Because this, perhaps, is the first study to assess the determinants of impoverishment due to OOP payment among female migrant head porters in Ghana, it was difficult to find literature that provides insights to this phenomenon. Further studies are therefore recommended to help understand the role of ethnicity in OOP health payment and impoverishment. The analysis showed significant association of period of engagement as a head porter and impoverishment due to OOP payments. It revealed that those who had a longer length of engagement as head-porters are somewhat protected from impoverishment due to OOP healthcare payment compared to those who had just joined the business. This situation could be suggestive of the fact that more experienced head porters develop coping strategies over time or are able to minimise health expenditure through a variety of health seeking ways. It is reasonable to suggest that head porters who have been in the trade for many years have been able to save enough money to support their health needs relative to those head porters who just joined the trade.

The city of migration destination was found to be one of the main determinants of impoverishment due to OOP payments among the adolescent female head porters. Respondents in Kumasi were more likely to be impoverished from OOP healthcare payments compared to those in Accra. The inference from this is that place of migration plays an important role in impoverishment. This high poverty level of migrant head porters in Kumasi relative to Accra appears to be consistent with the national picture-the Ghana Statistical Service estimated the incidence of poverty in the Ashanti Region in $2016 / 17$ to be $11.6 \%$ whereas it was $2.5 \%$ in the Greater Accra Region during the same period (Ghana Statistical Service, 2018).

Inactive NHIS membership status was one of the strongest predictors of impoverishment due to OOP healthcare payment. This is to be expected as most studies have shown that Ghana's health insurance has financial risk protection capabilities (Lattof, 2018; Nguyen et al., 2011) and that the NHIS actually contributes to declining rates of OOP payments in Ghana (Kanmiki et al., 2019). Studies from other countries including Nigeria and Vietnam also showed that people who were 
registered on a health insurance scheme were better protected from impoverishment due to OOP payment (Aregbeshola \& Khan, 2017; Van Minh \& Xuan Tran, 2012). A study on female head porters' enrolment, renewal and use of NHIS in Kumasi showed that a considerable number of the head porters were enrolled onto the NHIS and were found to be using it to access healthcare (Boateng et al., 2017). However, there were still several of them who were not registered and had challenges paying for healthcare (Boateng et al., 2017). Our findings in this study attest to the fact that registration and use of Ghana's National Health Insurance does necessarily protect the vulnerable from impoverishment due to healthcare payment. Our findings also revealed that although about $60 \%$ of respondents had registered with the NHIS, only $29 \%$ (around half) had active NHIS cards with which they could access healthcare under NHIS. Perhaps, the inability of the head-porters to renew and maintain active NHIS membership speaks to the issue of unaffordability of insurance premiums given that their minimum daily income ranges from $\mathrm{GH} \varnothing 2.0(\sim 0.4)$ in Accra to $\mathrm{GH} \varnothing 0.5(\sim \$ 0.1)$ in Kumasi. It is also reasonable to suggest that because the head-porters generally earn low incomes, they may prefer to use their money in other areas such as food consumption rather than paying for health insurance. In fact, earlier research reported that averagely, $61 \%$ of migrant adolescent girl head porters' monthly income is spent on health and food (Alatinga, 2019). Another study on health insurance status among migrant female head porters in Accra showed very low rates of active membership even though registration was a little over half of the study participants (Lattof, 2018). Lattof's study further showed that female head porters in Accra recognized the value of enrolment onto the health insurance (Lattof, 2018). However, availability of money for enrolment or renewal cost, perception about insurance enrolment costing more in Accra compared to the north and perception that paying OOP for care results in better quality of care were identified as the main reasons for low active enrolment of migrant female head porters on to the national health insurance programme (Atinga et al., 2015; Lattof, 2018).

Respondents' self-assessment of the severity of their sickness was significantly associated with impoverishment due to OOP payment in both bivariate and multivariate analyses. Previous studies in other settings have shown that the type of illness suffered is a predictor of impoverishment (Aregbeshola \& Khan, 2017). Severe illnesses especially those requiring hospitalization may require individuals or households to raise additional money through coping strategies such as borrowing or selling assets to pay for medical bills. For example, previous studies from 15 African countries suggest that when medical bills exceed household income, they tend to use savings, sell assets, borrow money from family and friends, money lenders or take out a loan from the bank to finance healthcare (Leive $\& \mathrm{Xu}, 2008$ ). Leive and $\mathrm{Xu}$ (2008) reported that borrowing and selling assets to finance healthcare ranged from $23 \%$ of households in Zambia to $68 \%$ in Burkina Faso. Kruk et al. (2009:1056) described borrowing and selling assets to finance healthcare as 'hardship financing', and reported that "one in four households in forty developing countries resort to hardship financing to pay for health care". Kruk et al. (2009) further reported that averagely, $25.9 \%$ of households borrowed money or sold items to pay for health care in developing countries. The process of borrowing money or selling assets to finance healthcare could result in impoverishment.

Like the severity of sickness, the place where care was sought when ill was also significant in the analyses. The results imply that drug stores and home treatment are associated with lower impoverishment. This is consistent with previous studies that have shown that the place where healthcare is sought when ill is strongly associated with vulnerability to poverty due to OOP payments (Aregbeshola \& Khan, 2017). Another study in Bangladesh also suggested that the use of private health facilities, including drug stores is associated with OOP payments and impoverishment (Ahmed et al., 2021). Ahmed et al. ( 2021) explained that 
households that sought healthcare from private health facilities had a 9.88 higher odds of facing catastrophic health expenditure and impoverishment relative to those who sought care from public health facilities.

\section{Ethical Consideration}

The proposal did not receive formal ethical review approval from any Scientific Ethical Review Committee/Board. However, the Department of Social Welfare under the auspices of the Ministry of Gender, Children and Social Protection, which has oversight responsibility over the head-porters, reviewed the research proposal/protocol to ensure that the research did not cause emotional or physical harm to the participants. We also sought permission from the Kayayei Association, and we were granted permission to access the participants. During data collection, the purpose of the study was explained to all study participants. Oral/verbal informed consent was obtained from participants before interviews were conducted. The study participants were also informed that their participation in the study was voluntary, and that they could withdraw from the study at any time without any consequences. The study participants were further assured of anonymity and confidentiality of the information provided.

\section{Limitations of the study}

The results of the study may not be generalizable to the entire population of head porters given that it is based on a sub-sample of only girls who were ill and sought care during the last 12 months. Characteristic of most surveys, recall bias is also a limitation of this study since respondents were required to provide information of cost over a 12month period. We also did not factor in indirect cost of seeking care and the income lost in the process of seeking care due to methodological challenges in quantifying the cost of those items within the informal sector. Nonetheless, the study provides a good picture regarding OOP and impoverishment among adolescent girl head porters in Ghana. Further studies on this phenomenon should include qualitative methods to help unearth the drivers of impoverishments from OOP payments and the push and pull factors contributing to the migration of these young vulnerable girls to the big cities of Ghana.

\section{Conclusion}

Ghana implemented a National Health Insurance Scheme (NHIS) to improve financial access to health care especially for the poor and vulnerable in society. Despite the existence of the NHIS, majority of migrant female head-porters in the informal sector still make OOP payments for health care. The high incidence of impoverishment due to OOP healthcare payments among this vulnerable adolescent female head porters merits prompt public policy attention. It is evident from this study that without financial risk protection for these migrant adolescent head porters, they could be pushed into poverty due to OOP healthcare payments. For this reason, the Ministries of Health and Gender, Children and Social Protection have to factor the needs of vulnerable migrants into restructuring of health systems and social protection programmes to ensure that they have access to affordable health care. Specifically, as internal migration is increasing in many settings, it is important for the Ministry of Gender, Children and Social Protection and the Ministry of Health to collaborate and target the migrant female headporters in the informal sector and enrol them onto the NHIS in order to increase their access to healthcare. Additionally, policy interventions including skills training should be provided by Government to increase income levels, and improve the poverty situation of adolescent girl head porters. We recommend that future research should explore the possible reasons for the association of ethicity with OOP induced poverty among the migrant female head porters.

\section{Acknowledgment}

The Council for the Development of Social Science Research in Africa (CODESRIA) supported the research for this paper under the African Diaspora support to African Universities program. 
CODESRIA however, did not play any role in the research design, data collection and writing of this paper. We acknowledge highly the hard work of the research assistants who collected the data as well as the Department of Social Welfare, under the Ministry of Gender, Children and Social Protection for all the support during the research process. We acknowledge also the Leadership of Kayayei Association who supported our research and gave us permission to talk to research participants.

\section{References}

Abiiro G. A. \& De Allegri M (2015) Universal health coverage from multiple perspectives: A synthesis of conceptual literature and global debates. BMC International Health and Human Rights 15:17.

Atinga R. A., Abiiro, G. A. \& Kuganab-lem, R (2015). Factors influencing the decision to drop out of health insurance enrolment among urban slum dwellers in Ghana. Tropical Medicine and International Health 20:312321.

Ahmed, S., Ahmed, M. W., Hasan, M. Z., Mehdi, G. G., Islam, Z., Rehnberg, C., Niessen, L. W., \& Khan, J. A. M. (2021). Assessing the incidence of catastrophic health expenditure and impoverishment from out-of-pocket payments and their determinants in Bangladesh: Evidence from the nationwide Household Income and Expenditure Survey 2016. International Health, ihab015. https://doi.org/10.1093/inthealth/ihab015

Akazili, J., Ataguba, J. E.-O., Kanmiki, E. W., Gyapong, J., Sankoh, O., Oduro, A., \& McIntyre, D. (2017). Assessing the impoverishment effects of out-of-pocket healthcare payments prior to the uptake of the national health insurance scheme in Ghana. BMC International Health and Human Rights, 17(1). https://doi.org/10.1186/s12914-0170121-7

Akazili, James, Welaga, P., Bawah, A., Achana, F. S., Oduro, A., Awoonor-Williams, J. K., Williams, J. E., Aikins, M., \& Phillips, J. F.
(2014). Is Ghana's pro-poor health insurance scheme really for the poor? Evidence from Northern Ghana. BMC Health Services Research, 14(1), 1-9. https://doi.org/10.1186/s12913-014-0637-7

Akweongo, P., Aikins, M., Wyss, K., Salari, P., \& Tediosi, F. (2021). Insured clients out-ofpocket payments for health care under the national health insurance scheme in Ghana. BMC Health Services Research, 21(1), 440. https://doi.org/10.1186/s12913-021-06401-8

Alatinga, K. A. (2019). Internal Migration, SocioEconomic Status and Remittances: Experiences of Migrant Adolescent Girl Head Porters in Ghana. African Human Mobility Review, 5(3), 1717-1749. https://sihma.org.za/journals/AHMR-Vol-5No-3-December-2019-pp-1674_1796.pdf

Aregbeshola, B. S., \& Khan, S. M. (2017). Determinants Of Impoverishment Due To Out Of Pocket Payments In Nigeria. Journal of Ayub Medical College, Abbottabad: JAMC, 29(2), 194-199. http://www.ncbi.nlm.nih.gov/pubmed/287182 30

Aryeetey, G. C., Westeneng, J., Spaan, E., JehuAppiah, C., Agyepong, I. A., \& Baltussen, R. (2016). Can health insurance protect against out-of-pocket and catastrophic expenditures and also support poverty reduction? Evidence from Ghana's National Health Insurance Scheme. International Journal for Equity in Health, 15(1), 116.

Attia-Konan, A. R., Oga, A. S. S., Touré, A., \& Kouadio, K. L. (2019). Distribution of out of pocket health expenditures in a sub-Saharan Africa country: Evidence from the national survey of household standard of living, Côte d'Ivoire. BMC Research Notes, 12(1), 1-8. https://doi.org/10.1186/s13104-019-4048-z

Awumbila, M., Owusu, G., \& Teye, J. (2014). Can rural-urban migration into slums reduce poverty? Evidence from Ghana. Migratingoutofpoverty.Dfid.Gov.Uk. http://migratingoutofpoverty.dfid.gov.uk/doc uments/wp-13---awumbila-owusu-teye-2014- 
can-rural-urban-migration-into-slums-reducepoverty-final.pdf

Boateng, S., Amoako, P., Poku, A. A., Baabereyir, A., \& Gyasi, R. M. (2017). Migrant female head porters' enrolment in and utilisation and renewal of the National Health Insurance Scheme in Kumasi, Ghana. Journal of Public Health, 25(6), 625-634. https://doi.org/10.1007/s10389-017-0832-1

Boerma, T., Eozenou, P., Evans, D., Evans, T., Kieny, M.-P., \& Wagstaff, A. (2014). Monitoring Progress towards Universal Health Coverage at Country and Global Levels. PLoS Medicine, 11(9), e1001731. https://doi.org/10.1371/journal.pmed.100173 1

Dalaba, M. A., Akweongo, P., Aborigo, R., Awine, T., Azongo, D. K., Asaana, P., Atuguba, F., \& Oduro, A. (2014). Does the National Health Insurance Scheme in Ghana reduce household cost of treating malaria in the KassenaNankana districts? Global Health Action, 7(November 2017), 23848. https://doi.org/10.3402/gha.v7.23848

Ekholuenetale, M., \& Barrow, A. (2021). Inequalities in out-of-pocket health expenditure among women of reproductive age: after-effects of national health insurance scheme initiation in Ghana. The Journal of the Egyptian Public Health Association, 96(1), 6. https://doi.org/10.1186/s42506-020-00064-9

Fenny, A. P., Yates, R., \& Thompson, R. (2018). Social health insurance schemes in Africa leave out the poor. International Health, 10(1), $1-3$. https://doi.org/10.1093/inthealth/ihx046

Fiestas Navarrete, L., Ghislandi, S., Stuckler, D., \& Tediosi, F. (2019). Inequalities in the benefits of national health insurance on financial protection from out-of-pocket payments and access to health services: Cross-sectional evidence from Ghana. Health Policy and Planning, 34(9), 694-705. https://doi.org/10.1093/heapol/czz093

Ghana Health Service. (2017). Ghana Health Service 2016 Annual Report (Issue June).
Ghana Statistical Service. (2018). Ghana Living Standards Survey (GLSS7): Poverty trends in Ghana; 2005-2017. In Ghana Statistical Service.

http://www.statsghana.gov.gh/docfiles/public ations/GLSS7/Poverty Profile Report_2005 2017.pdf

Gile, K. J., \& Handcock, M. S. (2010). 7. Respondent-Driven Sampling: An Assessment of Current Methodology. Sociological Methodology, 40(1), 285-327. https://doi.org/10.1111/j.1467-

9531.2010.01223.x

Gilmore, K. (2018). Migration and Adolescent Health. Journal of Adolescent Health, 63, 1215.

https://doi.org/10.1016/j.jadohealth.2018.05.0 09

Goudge, J., Russell, S., Gilson, L., Gumede, T., Tollman, S., \& Mills, A. (2009). Illnessrelated impoverishment in rural South Africa: Why does social protection work for some households but not others? Journal of International Development, 21(2), 231-251. https://doi.org/10.1002/jid.1550

Hailemichael, Y., Hanlon, C., Tirfessa, K., Docrat, S., Alem, A., Medhin, G., Lund, C., Chisholm, D., Fekadu, A., \& Hailemariam, D. (2019). Catastrophic health expenditure and impoverishment in households of persons with depression: A cross-sectional, comparative study in rural Ethiopia. BMC Public Health, 19(1), 930. https://doi.org/10.1186/s12889019-7239-6

International Organization for Migration. (2020). World Migration Report. https://publications.iom.int/system/files/pdf/ wmr_2020.pdf

Kanmiki, E. W., Bawah, A. A., Phillips, J. F., Awoonor-Williams, J. K., Kachur, S. P., Asuming, P. O., Agula, C., \& Akazili, J. (2019). Out-of-pocket payment for primary healthcare in the era of national health insurance: Evidence from northern Ghana. PLoS ONE, 14(8). https://doi.org/10.1371/journal.pone.0221146 
Kruk, M. E., Goldmann, E., \& Galea, S. (2009). Borrowing and selling to pay for health care in low- and middle-income countries. Health Affairs (Project Hope), 28(4), 1056-1066. https://doi.org/10.1377/hlthaff.28.4.1056

Kusi, A., Hansen, K. S., Asante, F. A., \& Enemark, U. (2015). Does the National Health Insurance Scheme provide financial protection to households in Ghana? BMC Health Services Research, 15(1), 1-12. https://doi.org/10.1186/s12913-015-0996-8

Lattof, S. R. (2018). Health insurance and careseeking behaviours of female migrants in Accra, Ghana. Health Policy and Planning, 33(4), 505-515. https://doi.org/10.1093/heapol/czy012

Leive, A., \& Xu, K. (2008). Coping with out-ofpocket health payments: Empirical evidence from 15 African countries. Bulletin of the World Health Organization, 86(11), 849-856. https://doi.org/10.2471/BLT.07.049403

Li, Y., Wu, Q., Xu, L., Legge, D., ... Y. H.-B. of the W., \& 2012, U. (2012). Factors affecting catastrophic health expenditure and impoverishment from medical expenses in China: policy implications of universal health insurance. SciELO Public Health. https://www.scielosp.org/article/bwho/2012.v 90n9/664-671/en/

National Health Insurance Authority. (2013). National health insurance authority 2013 annual report.

Nguyen, H. T., Rajkotia, Y., \& Wang, H. (2011). The financial protection effect of Ghana national health insurance scheme: Evidence from a study in two rural districts. International Journal for Equity in Health, 10(1), 4. https://doi.org/10.1186/1475-9276$10-4$

Okoroh, J., Sarpong, D. O. B., Essoun, S., Riviello, R., Harris, H., \& Weissman, J. S. (2020). Does insurance protect individuals from catastrophic payments for surgical care? An analysis of Ghana's National Health Insurance Scheme at Korle-Bu teaching Hospital. BMC Health Services Research, 20(1), 1-11. https://doi.org/10.1186/s12913-020-4887-2

Reichel, D., \& Morales, L. (2017). Surveying immigrants without sampling frames evaluating the success of alternative field methods. Comparative Migration Studies, 5(1), 1. https://doi.org/10.1186/s40878-0160044-9

Sabutey, V. K. (2014). Celebrating International Women's Day: a Look at the Plights of Ghanaian Female Porters (Kayayei) MyJoyOnline.com.

https://www.myjoyonline.com/opinion/2014/

March-11th/celebrating-internationalwomens-day-a-look-at-the-plights-ofghanaian-female-porters-kayayei.php

Salari, P., Di Giorgio, L., Ilinca, S., \& Chuma, J. (2019). The catastrophic and impoverishing effects of out-of-pocket healthcare payments in Kenya, 2018. BMJ Global Health, 4(6), e001809. https://doi.org/10.1136/bmjgh2019-001809

United Nations General Assembly. (2015). Sustainable Development goals: Transforming our world. In igbp.net. http://www.igbp.net/download/18.62dc35801 456272b46d51/1399290813740/NL82SDGs.pdf

Van Minh, H., \& Xuan Tran, B. (2012). Assessing the household financial burden associated with the chronic non-communicable diseases in a rural district of Vietnam. Global Health Action, 5, 1-7. https://doi.org/10.3402/gha.v5i0.18892

Wagstaff, A., Eozenou, P., \& Smitz, M. (2020). Out-of-pocket expenditures on health: A global stocktake. World Bank Research Observer, 35(2), 123-157. https://doi.org/10.1093/WBRO/LKZ009

Wagstaff, A., Flores, G., Hsu, J., Smitz, M. F., Chepynoga, K., Buisman, L. R., van Wilgenburg, K., \& Eozenou, P. (2018). Progress on catastrophic health spending in 133 countries: a retrospective observational study. The Lancet Global Health, 6(2), e169e179. https://doi.org/10.1016/S2214109X(17)30429-1 
Wagstaff, A., Flores, G., Smitz, M. F., Hsu, J., Chepynoga, K., \& Eozenou, P. (2018). Progress on impoverishing health spending in 122 countries: a retrospective observational study. The Lancet Global Health, 6(2), e180e192. https://doi.org/10.1016/S2214109X(17)30486-2

World Bank. (2016). Universal Health Coverage (UHC) in Africa : a framework for action (pp. $1-3)$.

http://documents.worldbank.org/curated/en/6 21351472470629641/Rumo-à-coberturauniversal-de-saúde-na-África-um-plano-deação

World Bank (2017). World Development Indicators. The World Bank. 1818 H Street NW, Washington DC 20433

World Health Organization. (2010). A conceptual framework for action on the social determinants of health: debates, policy \& practice, case studies. https://www.who.int/sdhconference/resources /ConceptualframeworkforactiononSDH_eng. pdf

World Health Organization. (2019). WHO | Refugee and migrant health. https://www.who.int/migrants/en/

World Health Organization. (1978). Primary Health Care: Alma-Ata. World Health Assem., Geneva: World Health Organization; 1978.

World Health Organization. (2010). World Health Report: Health systems financing: the path to universal coverage. In World Health Organization. World Health Organization. https://www.who.int/whr/2010/en/

Yiran, G.-S. A., Teye, J. K., \& Yiran, G. A. B. (2015). Accessibility and Utilisation of Maternal Health Services by Migrant Female Head Porters in Accra. Journal of International Migration and Integration, 16(4), 929-945. https://doi.org/10.1007/s12134-014-0372-2 